\title{
Oxidative Stress and Kidney Glycation in Rats Exposed Cadmium
}

\author{
Eko Suhartono, Triawanti, Amin Setyo Leksono, and M. Sasmito Djati
}

\begin{abstract}
Cadmium (Cd) is a heavy metal and it was proposed in the formation of Reactive Oxygen Species (ROS) and Advance Glycation End Products (AGEs). The role of $\mathrm{Cd}$ induced oxidative stress and glycation in kidney has not been much studied. Thus our study aimed to measure the oxidative stress and glycation in kidney exposed to $\mathrm{Cd}$. The present study was a true experimental study design to examine the impact of Cd exposure in renal rats (Rattus novergicus) male. The study involved 4 groups, K0 was the control group, while the other $(\mathrm{K} 1, \mathrm{~K} 2, \mathrm{~K} 3)$ was the case group with exposure of $\mathrm{Cd}$ in different concentration. For analyzing of the data, SPSS software version 17 was used and was examined by ANOVA test. The resulted showed that there are a significance differences of $\mathrm{MDA}, \mathrm{H}_{2} \mathrm{O}_{2}$, SOD activity and AOPP between case and control group, but there are not MG and CC are not sgnificance differences. Our study showed $\mathrm{Cd}$ induced oxidative stress but not caused glycation reaction.
\end{abstract}

Index Terms-AOPP, cadmium, glycation and oxidative stress.

\section{INTRODUCTION}

Cadmium (Cd) is heavy metals which used in many industry, including semiconductor, manufacturing, welding, soldering, ceramics and painting [1]. Roughly 13,000 tons of cadmium is produced worldwide each year for nickel-cadmium batteries, pigments, chemical stabilizers, metal coatings and alloys [2]. The Agency for Toxic Substances and Disease Registry (ATSDR) has listed Cd among the top seven of the 275 most hazardous substances in the environment [3], [4]. Cd remains a source of concern for industrial workers and for populations living in polluted areas, especially in developed countries [5].

$\mathrm{Cd}$ is hazardous both by inhalation and ingestion and can cause acute and chronic toxicity [6]. The routes of Cd intake involve the lungs, intestines and skin [7]. Cadmium in the body is predominantly bound to metallothioneins. The cadmium-metallothionein complex is distributed to various tissues and organs and is ultimately reabsorbed in kidney tubuli [7]. There is no mechanism for the excretion of

Manuscript received January 20, 2014; revised March 6, 2014.

Eko Suhartono is with Environmental Science and Technology Graduate Program, University of Brawijaya, Malang, Indonesia and Medical Chemistry/Biochemistry Department Faculty of Medicine University of Lambung Mangkurat, Banjarmasin, Indonesia (e-mail: ekoantioxidant@gmail.com).

Triawanti is with Medical Chemistry/Biochemistry Department, Faculty of Medicine, University of Lambung Mangkurat, Banjarmasin, Indonesia (e-mail: tria_fkunlam@yahoo.co.id).

Amin Setyo Leksono and M. Sasmito Djati are with the Biology Department, Faculty of Mathematics and Natural Sciences, University of Brawijaya, Malang, Indonesia (e-mail: leksono72@yahoo.com; msdjati@ub.ac.id). cadmium in humans. Thus $\mathrm{Cd}$ can accumulates throughout a lifetime inside the body. The half-life of cadmium in kidney cortex is 20-35 years [7].

Acute exposure to $\mathrm{Cd}$ causes dysuria, polyuria, chest pain, fatigue and headache [8]. Chronic poisoning typically was found to have occurred after several years of exposure and was characterized clinically by variable features of nasorespiratory involvement, such as emphysema, rhinitis, alteration of nasal mucosa, and anosmia, and by renal tubular dysfunction. Yellow tooth discolouration, mild anaemia, and disturbances in calcium metabolism, osteomalacia, and renal toxicity also were observed occasionally [9]. In humans, the largest amount of $\mathrm{Cd}$ is deposited in the kidneys, liver, pancreas and lungs [7], [10].

Clinical kidney damage has been demonstrated mainly in connection with occupational exposure. However, in the past couple of decades, exposure to level of cadmium found in the general population has been shown to result in subtle effects on the kidney, for example on renal tubular markers and bone [11]. Kidney cadmium have been measured both at autopsy and in vivo [9].

The mechanism Cd damage the kidney might through the formation of Reactive Oxygen Species (ROS) [12] and Advance Glycation End Products (AGEs) by nonenzymatic reaction [13].

The nonenzymatic reaction between reducing sugars and proteins, known as glycation, has received increased attention in nutritional and medical research. Nonenzymatic glycation is a complex series of reactions between reducing sugars and amino compounds [14].

The previous study described that the reaction of MG with ceruloplasmin may lead to decreased feroxidase activity in vitro [15]. In addition, the ferritin/MG/lysine system may lead to oxidative DNA damage via the generation of ROS by the Fenton-like reaction of free iron ions released from oxidatively damaged ferritin [16]. Based on previous research, methylglyoxal formation can be accelerated by metals in vitro. The proposed mechanism explained that the metal $\mathrm{Mn}+$ (e.g., $\mathrm{Fe}^{2+}, \mathrm{Cu}^{2+}$, and so on) can catalyze the 2,3-enediol and formed $\mathrm{MG}$ and hydroperoxide [17]. The role of $\mathrm{Cd}$ in the formation of MG and Carbonyl Compound (CC) has not been much studied.

Various studies have been made on the cadmium-induced oxidative stress on kidney. Kevin Dzobo et al 2013, showed that $\mathrm{Cd}$ induced oxidative stress and depletes antioxidant enzymes in rat kidneys and testes [18]. In other studies of 95 patients Chronic Kidney Disease (CKD) in India showed that the serum MDA level was significantly raised and serum SOD level registered a significant decline in both non dialysis and hemodialysis groups compared with control. The SOD 
activity is decreased in CKD patients owing to increased ROS load such as hydrogen peroxide, which is a known suppressant of SOD activity [19].

ROS compounds were involved in production of advance oxidation protein products (AOPP) AOPP is dityrosine containing cross linked protein products, a definition that is important as it excludes protein aggregates that are formed by disulphide bonds as a result of oxidative stress. Therefore, AOPP is a good oxidative stress marker, which originates under oxidative and carbonyl stress and increase global inflammatory activity [20]-[24].

AOPPs are not innocent end products of activation of macrophages: they are biologically active molecules capable of mediating oxidative stress and respiratory burst in monocytes [25].

At the respiratory burst, there was a rapid uptake of molecular oxygen and transformation into reactive oxygen compounds, which is a representation of the host defense mechanisms in the inflammatory site. It is important that relevant reactive oxygen compounds physiological concentrations able to modulate the redox-sensitive signaling cascade and improve immunological cellular function [26]. Our study aims to measure oxdative stress and glycation in kidney exposed to $\mathrm{Cd}$.

\section{MATERIAL AND METHODS}

The present study was a true experimental study design to examine the impact of $\mathrm{Cd}$ exposure in renal rats (Rattus novergicus) male, Sprague-Dawley furrow, healthy and have normal activity with 8-10 weeks of age and weighing $300 \pm 10$ grams.

All rats were caged separately for adaptation for one week. During the acclimation period and the mice were fed the same drinking water treatment period, ie C-05 pellets and PDAM water as drinking water. Before being treated, rats were fasted for 1-2 hours would be to ensure that the rat stomach empty.

The study involved 4 groups of 40 female rats (Rattus novergicus), where one group (K0) was the control group, while the other was the case group with exposure of $\mathrm{Cd}$. The control group rats were given $2 \mathrm{ml}$ of distilled water with a sonde every morning while in the treatment group rats were exposed $\mathrm{Cd}$ in the different concentration. $K 1=$ administration of $\mathrm{Cd} 0.003 \mathrm{mg} / \mathrm{L}, K 2=\mathrm{Cd}$ administration of $0.3 \mathrm{mg} / \mathrm{L}$, and $K 3=\mathrm{Cd}$ administration of $3 \mathrm{mg} / \mathrm{L}$. All groups of rats were provided ad libitum for 4 weeks.

After rats is surgery, serum and kidneys were taken and immediately fixed in phosphate buffer solution $\mathrm{pH}$ 7. Then the kidney was cut into small pieces and ground to form a liquid. Subsequently, $5 \mathrm{ml}$ of the solution was taken and centrifuged at $3500 \mathrm{rpm}$ for 10 minutes. The top layer of 200 $\mathrm{mL}$ were taken to be examined.

\section{A. Hydrogen Peroxide Assay}

Determination of $\mathrm{H}_{2} \mathrm{O}_{2}$ concentration by the modified FOX2 method [27]. Solutions measured spectrophotometrically at $\lambda=505 \mathrm{~nm}$. Standard and test solutions consisted of $1 \mathrm{M} \mathrm{H}_{2} \mathrm{O}_{2} 200 \mu \mathrm{L}$ and $200 \mu \mathrm{L}$ serum, respectively, with the addition of $160 \mu \mathrm{L}$ PBS pH 7.4, $160 \mu \mathrm{L}$ $\mathrm{FeCl}_{3}$ (251.5 mg FeCl 3 dissolved in $250 \mathrm{ml}$ distilled water) and $160 \mu \mathrm{L}$ o-fenantroline (120 mg o-phenantroline dissolved in $100 \mathrm{ml}$ distilled water) for both solutions. The composition of the blank solution was identical to that of the test solution, except for absence of $\mathrm{FeCl}_{3}$ in the blank. Subsequent to preparation, all solutions were incubated for 30 minutes at room temperature, then centrifuged at $12,000 \mathrm{rpm}$ for 10 minutes, and the absorbance of the standard (As), test (Au) and blank (Ab) solutions measured at $\lambda=505 \mathrm{~nm}$, using the supernatant of each solution.

\section{B. Malondyaldehide Assay}

MDA was measured by the method of Buege and Aust [28]. The colour was measured spectrophotometrically at $532 \mathrm{~nm}$. Serum in the homogenization of $100 \mathrm{mg}$. Then add $1 \mathrm{~mL}$ aquadest then disposed of in thee pendorf. After that added $100 \%$ TCA $100 \mathrm{uL}, 1 \%$ Na-Thio $100 \mathrm{uL}$ and $250 \mathrm{uL}$ of $1 \mathrm{~N}$ $\mathrm{HCl}$. The solution is heated at a temperature of $1000 \mathrm{oC}$ for 20 minutes. Then centrifuged to $3500 \mathrm{rpm}$ for 10 minutes. Supernatant was taken. After that, add distilled water up to $3500 \mathrm{uL}$. The result is read by a spectrophotometer with a maximum wavelength of 500-600 $\mathrm{nm}$.

\section{Superoxide dismutase Assay}

The SOD activity in supernatant was measured by the method of Misra and Fridovich [29]. The supernatant $(500 \mu \mathrm{l})$ was added to $0.800 \mathrm{ml}$ of carbonate buffer (100 mM, pH 10.2) and $100 \mu \mathrm{l}$ of epinephrine $3 \mathrm{mM}$ ). The change in absorbance of each sample was then recorded at $480 \mathrm{~nm}$ in spectrophotometer for $2 \mathrm{~min}$ at an interval of $15 \mathrm{sec}$.

\section{Methylglyoxals Assay}

Methylglyoxals are estimated according to the modified method of Racker [22]. Twenty-five $\mu$ of samples was added to $350 \mu \mathrm{l}$ of DNPH [0.1\% DNPH in $2 \mathrm{~N} \mathrm{HCl}$ ]. Then to each tube $2.125 \mathrm{ml}$ of distilled water was added. Then it was incubated for 15 minutes at $37^{\circ} \mathrm{C}$. After the incubation $1.5 \mathrm{ml}$ $10 \% \mathrm{NaOH}$ was added and absorbance was read at $576 \mathrm{~nm}$ using spectrophotometer. MG levels are expressed in percent absorbance MG and dicarbonyl absorbance [30].

\section{E. AOPP Assay}

Kidney homogenat AOPP measurement were made by spectrophotometric methods as describe by Witko-Sarsat et al [31].

\section{F. Carbonyl Compound Assay}

Sample derivatization. Two $1-\mu \mathrm{L}$ aliquots are needed for each sample to be assayed. Samples are extracted in a final concentration of $10 \%(\mathrm{w} / \mathrm{v})$ TCA. The precipitates are treated with $500 \mu \mathrm{L}$ of $0.2 \% \mathrm{DNPH}$ or $500 \mu \mathrm{L}$ of $2 \mathrm{M} \mathrm{HCl}$. Samples are incubated at room temperature for $1 \mathrm{~h}$ with vortexing at 5 -min intervals. The proteins are then precipitated by adding $55 \mu \mathrm{L}$ of $100 \%$ TCA. The pellets are centrifuged and washed three times with $500 \mu \mathrm{L}$ of the ethanol:ethyl acetate mixture. The pellet is then dissolved in $600 \mu \mathrm{L}$ of $6 \mathrm{M}$ guanidine hydrochloride. The carbonyl content is determined by reading the absorbance at the optimum wavelength $390 \mathrm{~nm}$ [28].

\section{G. Statistical Analysis}

Data are presented as means \pm SD. The differences were examined by the ANOVA test. For all outcomes, a nominal 
$p$-value of $p<0.05$ was considered significant.

\section{RESULT AND DISCUSSION}

TABLE I: SOD ACTIVITY, $\mathrm{H}_{2} \mathrm{O}_{2}$ AND MDA LEVELS IN SERUM RATS EXPOSED TO CADMIUM

\begin{tabular}{|l|c|c|c|c|c|}
\hline Parameters & $K 0$ & $K 1$ & $K 2$ & $K 3$ & $P$ \\
\hline \multirow{2}{*}{$\mathrm{MDA}(\mu \mathrm{M})$} & $529 \pm$ & $567,38 \pm$ & 567,38 & 704,63 & 0,000 \\
& 34,95 & 48,32 & $\pm 48,32$ & $\pm 56,85$ & \\
\hline \multirow{2}{*}{$\mathrm{H}_{2} \mathrm{O}_{2}(\mu \mathrm{M})$} & $4,35 \pm$ & $12,72 \pm$ & $12,72 \pm$ & $18,35 \pm$ & 0,000 \\
& 0,80 & 4,11 & 4,11 & 2,70 & \\
\hline $\mathrm{SOD}(\mathrm{IU} / \mathrm{mL}$ & $12,81 \pm$ & $12,73 \pm$ & $12,73 \pm$ & $8,08 \pm$ & 0,004 \\
enzim $)$ & 2,33 & 2,51 & 2,51 & 2,62 & \\
\hline
\end{tabular}

The average levels of MDA, $\mathrm{H}_{2} \mathrm{O}_{2}$ and SOD activity are presented in Table I. ANOVA test results showed (Table I) that there were significant differences between case and control groups $(p<0.05)$. The increased of $\mathrm{H}_{2} \mathrm{O}_{2}$ levels and decreased of SOD activity indicates that oxidative stress has occurred in rats exposed to $\mathrm{Cd}$.

Occupational exposure to $\mathrm{Cd}$ has been associated with occurence of increased oxidative stress. Oxidative stress is a harmful condition that occurs when there is an inbalance between ROS, including superoxide, hydrogen peroxide and hydroxyl radicals, and/or by inadequate antioxidative defences, including SOD, catalase, and peroxidase. An interesting mechanism explaining the indirect role of $\mathrm{Cd}$ in free radical generation was presented some years ago [10].

SOD is considered a key enzyme in the regulation of intracellular concentrations of ROS. SOD acts as the first line of defense against ROS, dismutating superoxide to $\mathrm{H}_{2} \mathrm{O}_{2}$. SOD acts as the first line of defense against ROS, dismutating superoxide to $\mathrm{H}_{2} \mathrm{O}_{2}$. Thus, increased SOD activity showed that it plays a positive role in controlling the cellular level of these ROS and/or repairing oxidative damage against free radicals by $\mathrm{Cd}$ stress [32].

$\mathrm{H}_{2} \mathrm{O}_{2}$ is an even less reactive species that is uncharged and can diffuse across membranes through aquaporins. Despite its low reactivity, some proteins contain specific cysteine residues that are prone to oxidation by hydrogen peroxide, which are critical to hydrogen peroxide-based signaling systems. $\mathrm{H}_{2} \mathrm{O}_{2}$ can be converted to the radical hydroxyl, a highly reactive species. $\mathrm{H}_{2} \mathrm{O}_{2}$ and other toxic oxygen species production in cellular compartments and result in acceleration of lipid peroxidation and other oxidative damage [33], [34].

The increased of MDA levels in serum rats exposed to $\mathrm{Cd}$ indicate the increased of lipid peroxidation. It is known that metal-induced generation of oxygen radicals results in the attack of not only DNA but also other cellular components involving polyunsaturated fatty acid residues of phospholipids, which are extremely sensitive to oxidation [12].

The overall process of lipid peroxidation consists of three stages: initiation, propagation and termination. Initiation, the first stage, involves the attack of a ROS capable of abstracting a hydrogen atom from a methylene group in the lipid. The presence of a double bond adjacent the methylene group weakens the bond between carbon and hydrogen so the hydrogen can be more easily removed from the fatty acid molecule. Fatty acids with no double bonds or with onedouble bond can undergo oxidation but not a chain lipidperoxidation process [7].

The process of hydrogen abstraction leaves behind a fatty acid having one unpaired electron. When oxygen is present in the surrounding tissues, the fatty acid radical can react with it leading to the formation of lipo-peroxyl radicals (ROO•). Once formed, lipo-peroxyl radicals (ROO•) can be rearranged via a cyclization reaction to endoperoxides (precursors of malondialdehyde) with the final product of peroxidation process being MDA. MDA is mutagenic in bacterial and mammalian cells and carcinogenic in rats. Increase in lipid peroxidation with increased MDA levels has been observed in a cadmium-induced experimental group of wistar albino rats. It has been reported in other research that administration of $\mathrm{Cd}$ via different routes causes increased lipid peroxidation in membranes of erythrocytes and tissues such as the liver, kidney, brain and testes where MDA is used as an indicator of oxidative damage [4], [7], [12].

MDA is one of the main manifestations of oxidative damage and has been found to play an important role in the toxicity of $\mathrm{Cd}$. MDA is well-known lipid peroxidation indicator and has been found to increase in the liver and kidneys after Cd exposure. Eko Suhartono et al. 2013 in his research showed that the administration of $\mathrm{Cd}$ caused significantly increase of MDA and peroxide levels as compared to the control group $(p<0.05)$ [4], [30]. The results of other studies showed that ethanol and $\mathrm{Cd}$ increased the serum and liver MDA concentrations $24 \mathrm{~h}$ after administration [4]. Haki Kara et al 2002 suggest that single doses of different concentrations of $\mathrm{Cd}$ are administered the dose dependent increase in MDA levels in agreement with this knowledge [35].

TABLE II: AOPP, CC AND MG LEVELS IN RENAL RATS EXPOSED TO CADMIUM

\begin{tabular}{|l|c|c|c|c|c|}
\hline Parameters & $K 0$ & $K 1$ & $K 2$ & $K 3$ & $P$ \\
\hline \multirow{2}{*}{ AOPP $(\mu \mathrm{M})$} & $4,51 \pm$ & $6,55 \pm$ & $6,83 \pm$ & $9,40 \pm$ & 0,000 \\
& 0,23 & 0,45 & 0,61 & 1,40 & \\
\hline Carbonyl & $2,55 \pm$ & $2,93 \pm$ & $2,81 \pm$ & $3,20 \pm$ & 0,208 \\
Compound $(\mathrm{nM})$ & 0,99 & 0,42 & 0,52 & 0,40 & \\
\hline Methylglyoxal & $20,88 \pm$ & $25,39 \pm$ & $29,49 \pm$ & $29,73 \pm$ & 0,232 \\
$(\%)$ & 5,41 & 5,21 & 9,73 & 8,62 & \\
\hline
\end{tabular}

The levels of AOPP, CC and MG was evaluated. ANOVA test resulted showed that there were not significant diffrences in the levels of CC and MG.

Heavy metal was proposed in the formation of advance glycation end products (AGEs) by nonenzymatic reaction. Glycation is nonenzymatic reaction between reducing sugars and proteins. Voziyan et al proposed that heavy metal can accelerate the formation of compounds dicarbonyl [e.g., glyoxal (GO), methylglyoxal (MG) and 3 deoxyglucosone] [13], [14].

MG as a side-product of glycolysis arises from an increased flux during hyperglycemia. MG has been postulated to play a role in the development of hypertension [36]. Studies using animal model and cell cultures showed a significant increase in blood pressure to coincide with elevated MG level in plasma and aortic tissues [37], [38]. However, functional links between MG biogenesis and hypertension, in part 
mediated by ROS and AGEs, have only been documented in rat model but not yet in humans under these conditions.

In Table II shows that increasing concentrations of $\mathrm{Cd}$ has no Increased levels of $\mathrm{Cd}$ does not make a significant difference in kidney rats. That indicates that exposure to $\mathrm{Cd}$ is not caused glycation reactions in the kidneys. On the other hand exposure to $\mathrm{Cd}$ caused an increasing of AOPP level that indicates $\mathrm{Cd}$ caused inflammation in kidney rats.

According to previous studies AOPP may represent a novel class of proinflammatory mediators acting as a mediator of oxidative stress and monocyte respiratory burst. The monocyte is thus, at the same time, the elective cellular target of AOPP and a potential source of oxidants inducing AOPP [31].

A close correlation was observed between AOPP and neopterin, the monocyte activation marker. This selective relationship between AOPP and monocyte activation was further established with positive correlations between AOPP and TNF- $\alpha$ and its soluble receptors, and, to a lesser degree, with IL-1Ra, although these correlations tended to be of only borderline significance when values were corrected for creatinine clearance [22].

Exposure of $\mathrm{Cd}$ activated cells to form a reactive oxygen compounds. This event called respiratory burst involving the NADPH oxidase activation. At the respiratory burst, there was a rapid uptake of molecular oxygen and transformation into reactive oxygen compounds, which is a representation of the host defense mechanisms in the inflammatory site. It is important that relevant reactive oxygen compounds physiological concentrations able to modulate the redox-sensitive signaling cascade and improve immunological cellular function [24].

Reactive oxygen species such as hydrogen peroxide, superoxide anion, hydroxyl radical, etc can trigger oxidative damage to macromolecules, leading to lipid peroxidation, amino acid chains oxidation, cross links protein formation, polypeptide chain oxidation forming protein fragmentation, DNA strands ruptured. Radical oxygen compounds were involved in production of AOPP [25].

In the past, studies on the interactions between proteins and oxidants have focused on the structural changes induced by oxidants generated by water pulse radiolysis, including superoxide and hydroxyl radicals. Such studies have demonstrated that structural modifications of proteins (selective loss of an amino acid, fragmentation, or aggregation) were highly dependent on the nature of the oxidant. The formation of AOPP could be induced in control plasma by chlorinated oxidants such as chloramines or hypochlorus acid. Of note, the in vitro formation of AOPP was much lower when proteins were submitted to $\mathrm{H}_{2} \mathrm{O}_{2}$ compared to identical concentrations of chlorinated oxidants. Moreover, the formation of AOPP using purified human serum albumin waqs clearly correlated to the concentration of chlorinated oxidant added [31].

Since AOPP formation is optimal with chlorinated oxidants, it is interesting to speculate that its formation in vivo might result from enzymatic activity of phagocyte-derived Myelopeoxidase (MPO) [22].

AOPPs are produced during oxidative stress and inflammation as a result of MPO activity in activated neutrophils acting on hypochloric acid and chloramines; these are a reliable marker to measure the oxidative modification of proteins [39]. MPO is an haeme-containing enzyme which secreted by the phagocytes after an activation from respiratory burst system. MPO are usually used as tissues neutrophil accumulation and neutrophil activity marker on plasma assays. Myeloperoxidase use hydrogen peroxides to oxidize amount of aromatic species ( $\mathrm{RH})$ by one electron mechanism to form aromatic radical $(\mathrm{R} \bullet)$. This is typical, therefore they are ready to oxidize the strong non radical reactive oxygen species, the $\mathrm{HOCl}$ ions. $\mathrm{HOCl}$ is reactive oxygen species that produced by neutrophils and very bactericidals [17].

\section{CONCLUSION}

The results of this study concluded that exposure to cadmium causes oxidative stress in the kidneys, but not caused glycation reaction.

\section{ACKNOWLEDGMENT}

The authors are grateful to the financial support of School of Medicine, Lambung Mangkurat University in funding this project through the Faculty Research grant.

\section{REFERENCES}

[1] W. Adjar, F. A Rahaju, R. T Firdaus, and S. Eko, "The role of urinanry cadmium and lead level on pregnant women renal function," JOMB, vol. 3, no. 1, pp. 55-58, March 2014.

[2] M. Valko, H. Morris, and M. T. D Cronin, "Metals, toxicity and oxidative damage," Current Medicinal Chemistry, vol. 12, no. 10 , 2005.

[3] R. Wittman and H. Hu, "Cadmium exposure and nephropathy in a 28-year-old female metals worker," EHP, vol. 110, pp. 1261-1266, 2002 .

[4] E. Suhartono, Triawanti, A. Yunanto, R. T. Firdaus, and Iskandar, "Chronic Cadmium hepatooxidative in rats: Treatment with Haruan fish (Channa striata) extract," APCBEE Procedia, vol. 5, pp. 441-445, 2013.

[5] A. Bernard, "Cadmium \& Its adverse effects on human health," IJMR, vol. 128 , pp. 557-564, Oct. 2008.

[6] C. Y. Lin, M. Wu, J. A. Bloom, I. J. Cox, and M. Miller, "Rotation, scale, and translation resilient public watermarking for images," IEEE Trans. Image Process., vol. 10, no. 5, pp. 767-782, May 2001.

[7] K. Jornova and M. Valko,"Advances in metal-induced oxidative stress and human disease," Toxicology, vol. 283, pp. 65-87, 2011.

[8] E. Suhartono, Triawanti, A. Yunanto, R. T. Firdaus, and Iskandar, "Chronic cadmium hepatooxidative in rats: Treatment with Haruan fish (Channa striata) extract," APCBEE Procedia, vol. 5, pp. 441-445, 2013

[9] H. C. Gonick, "Nephrotoxicity of cadmium and lead," Indian J Med Res, vol. 128, pp. 335-352, October 2008.

[10] S. J. S. Flora, Megha Mittal and Ashish Mehta," Heavy metal induced oxidative stress \& its possible reversal by chelation therapy," Indian $J$ Med Res, vol. 128, pp. 501-523, October 2008.

[11] L. Barregard, E. F Lagging, T. Lundh, J. M. Olne, M. Wallin, M Olausson, C. Modigh and G. Sallsten, "Cadmium, mercury, and lead in kidney cortex of living kidney donors : Impact of different exposure sources," Env Res, vol. 1, pp. 1-8, October 2009.

[12] M. Valko, D. Leibfritz, J. Moncol, M. T. D. Cronin, M. Mazur, and J. Telser, "Free radicals and antioxidants in normal physiological function and human disease," IJBCB, vol. 39, pp. 44-84, 2007.

[13] P. A. Voziyan, R. G. Khalifah, C. Thibaudeau, A. Yildiz, J. Jacob, A. S. Serianni, and B. G. Hudson, "Modification Of proteins in vitro by physiological levels of glucose," $J B C$, vol. 278, no. 47, pp. 46616-46624, Nov. 2003.

[14] T. W. C. Lo, M. E. Westwood, A. C. Mclellan, T. Selwood, and P. J. Thornalleys, "Binding and modification of proteins by methylglyoxal under physiological conditions: A kinetic and mechanistic study with 
Na-Acetylarginine, Na-Acetylcysteine, and Na- Acetyllysine, and bovine serum albumin," JBC, vol. 269, no. 51, pp. 32299-32305, Dec. 1994.

[15] J. H. Kang, "Oxidative modification of human ceruloplasmin by methylglyoxal: An in vitro study," $J B M B$, vol. 39, no. 3, pp. 335-338, May 2006.

[16] S. H. An and J. H. Kang, "Oxidative damage of DNA induced by the reaction of methylglyoxal with lysine in the presence of ferritin," $B M B$ Reports, vol. 46, no. 4, pp. 225-229, 2013

[17] J. Valencia, S. Weldon, and D. Quinn, "Advanced glycation end product ligand for the receptor advanced glycation end product: Biochemical characteristic and formation kinetic," Analytic Biochem, vol 324, pp. 68-78, 2004

[18] K. Dzobo and Y. S. Naik, "Effect of selenium on cadmium-induced oxidative stress and esterase activtiy in rat organs," S Afr J Sci, vol. 109 no. 5/6, pp. 1-8, 2013.

[19] D. S. S. K. Raju, D. L. Lalitha, and P. Kiranmayi, "A Study of Lipid Profile and Lipid Peroxidation in Chronic Kidney Disease with Special Reference to Hemodialysis," J Clinic Res Bioeth, vol. 4, no. 143, pp. 1-5, 2013.

[20] A. Yunanto, R. T Firdaus, Triawanti, and E. Suhartono, "Advance Oxidation Protein Products (AOPPs) of Newborn at Risk of Sepsis as Novel Parameter for Early-Onset Neonatal Sepsis," IJBBB, vol. 4, no. 2 March 2014

[21] B. Veyseller, F. Aksoy, B. Ertas, M. Keskin, O. Ozhuran, Y. S. Yilldirum, F. G. I. Bayraktar, and H. Ozturk, "A new oxidative stress marker in patients with nasal polyposis: advance oxidation protein products (AOPP)," B-ENT, vol. 6, pp. 105-109, 2010.

[22] M. Skvarilova, A. Bulava, D. Stejskal, S. Adamovska, and J. Bartek, "Increased level of advanced oxidation protein products (AOPP) as a marker of oxidative stress in patients with acute coronary syndrome," Biomed. Papers, vol. 149, no. 1, pp. 83-87, June 2005.

[23] K. Simon, M. Warwas et al., "Advanced oxidation products and inflammatory markers in liver cirrhosis: A comparison between alcohol-related and HCV-related cirrhosis," Acta BP, vol. 58, no. 1, pp. 59-65, Mar. 2011.

[24] A. Aminullah, D. Gatot, M. S. Kosim, R. Rohsiswatmo, F. Indarso, and R. Dharma et al., Penatalaksanaan Sepsis Neonatorum, Jakarta: Health Technology Assessment Indo.

[25] Katarina S, Kristına K, J. Ferenczov, J. Hedvig, L. Podrack, and A. Heidland, "Advanced oxidation protein products and advanced glycation end products in children and adolescents with chronic renal insufficiency," Journal of Renal Nutrition, vol. 22, no. 1, pp. 143-148, January 2012.

[26] A. Yunanto, H. M. S. C. Kusuma, E. Widjajanto, and M. A. Widodo, "Kuantitas, kualitas, dan daya fagositosis neutrofil pada saliva dan darah bayi baru lahir dengan faktor risiko sepsis," $J K B$, vol. 27, no. 2, Aug. 2012

[27] D. Banerjee, P. A. Kumar, B. Kumar, U. K. Madhusoodanan, S. Nayak and J. Jacob, "Determination of absolute hydrogen peroxide concentration by spectrophotometric method," Current Science, vol. 83 , no. 10, Nov. 2002.

[28] U. K. Mishra, S. E. Jacobs, L. W. Doyle, and S. M. Garland, "Newer approaches to the diagnosis of early onset neonatal sepsis," ADCFN, vol. 91, pp. F208-F212, 2006.

[29] H. P. Misra and I. Fridovich, "The role of superoxide anion in the autooxidation of epinephrine and a simple assay for superoxide dismutase," JBC, vol. 247, no.10, pp.3170-3175, June 1972.

[30] U. K. Biswas, S. Banerjee, A. Das, and A. Kumar, "Elevation of serum methylglyoxal may be used as a screening marker in oral premalignant lesions," Biomed Res, vol. 22, no. 3, pp. 273-278, 2011.

[31] V. W. Sarsat, M. Friedlander, T. N. Khoa, C. C. Blandin, A. T. Nguyen, S. Canteloup, J. M. Dayer, P. Jungers, T. Driieke, and B. D. Latscha, "Advanced oxidation protein products as novel mediators on inflammation and monocyte activation in chronic renal failure," $J$ Immunol, vol. 161, pp. 2524-2532, 1998.
[32] K. Muthukumar and V. Nachiappan, "Cadmium-induced oxidative stress in Saccharomyces cerevisiae," Indian J. Biochem. Biophys, vol. 47, pp. 383-387, December 2010.

[33] T. Chang and L. Wu, "Methylglyoxal, oxidative stress, and hypertension," CJPP, vol. 84, pp. 1229-1238, 2006.

[34] H. Kara, F. Karata, and H. Canatan, "Effect of single dose cadmium chloride administration on oxidative stress in male and female rats," Turk J Vet Anim Sci, vol. 29, pp. 37-42, 2005.

[35] P. Newsholme, E. Rebelato, F. Abdulkader, M. Krause, A. Carpinelli, and R. Curi, "Reactive oxygen and nitrogen species generation, antioxidant defenses, and -cell function: a critical role for amino acids," Journal of Endocrinology, vol. 214, pp. 11-20, 2012.

[36] T. Chang and L. Wu, "Methylglyoxal, oxidative stress, and hypertension," CJPP, vol. 84, pp. 1229-1238, 2006.

[37] X. Wang, K. Desai, T. Chang, and L. Wu, "Vascular methylglyoxal metabolism and the development of hypertension," J Hypertens, vol. 23, pp. 1565-1573, 2005.

[38] E. Suhartono, Triawanti, A. S. Leksono, and M. S. Djati, "The role of cadmium in protein glycation by glucose: formation of methylglyoxal and hydrogen peroxide in vitro," JOMB, vol. 3, no. 1, pp. 59-62, March 2014

[39] E. M. Ellis, "Reactive carbonyls and oxidative stress: potential for therapeutic intervention," Pharmacology \& Therapeutics, vol. 115, pp. 13-24, 2007.

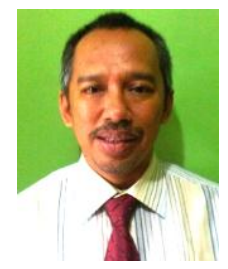

Eko Suhartono was born in Surabaya, Indonesia, in September 1968. He received his bachelor degree from Sepuluh Nopember of Institute Technology in 1991 and M. Sc degree in 1998 from Gadjah Mada University, Yogyakarta, Indonesia. He is currently studying environmental science and technology graduate program in Brawijaya University, Malang, Indonesia. His research is mainly focused on free radical and natural product antioxidant, ecotoxicology. ers.

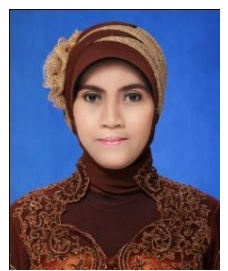

Triawanti was born in Surabaya, Indonesia, in September 1971. She received her medical doctor in 1998 from Lambung Mangkurat University, Banjarbaru, Indonesia, the M. Sc degree in 2002 from Airlangga University, Surabaya, Indonesia, and her Ph. D in 2012 from Brawijaya University, Malang, Indonesia. She is currently a lecturer and resercher in Faculty of Medicine Lambung Mangkurat University, Banjarmasin, Indonesia.

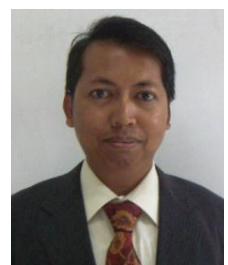

Amin Setyo Leksono was born in Pati, Indonesia, in November 1972. He received his Diploma of Science and M. Sc degree in 1997 and 2001 from Institute of Technology, Bandung, Indonesia, and his Ph.D in 2005 from Hiroshima University, Hiroshima, Japan. His research focused in entomology and ecology.

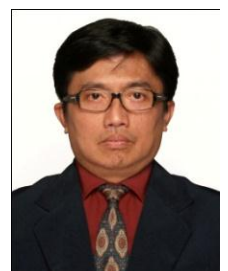

Mochammad Sasmito Djati was born in Yogyakarta, Indonesia, in March 1961. He recieved his engineer degree in 1985 from Brawijaya University, Malang, Indonesia, his M. Sc in 1989 from Padjajaran University, Bandung, and his Ph. D in 1997 from Okayama University, Japan. His research mainly focused in animal cell culture and biotechnology. 